\title{
A critical scientific review on South African governance of genetically modified organisms (GMOs)
}

\author{
F. W. Jansen van Rijssen ${ }^{1}$, E. Jane Morris ${ }^{2}$ and J. N. Eloff ${ }^{1 *}$ \\ ${ }^{1}$ Phytomedicine Programme, Department of Paraclinical Sciences, Faculty of Veterinary Science,University of Pretoria, \\ Private Bag X04, Onderstepoort, 0110, South Africa. \\ ${ }^{2}$ Department of Biochemistry, Faculty of Natural and Agricultural Sciences, University of Pretoria and African Centre for \\ Gene Technologies, PO Box 75011, Lynnwood Ridge 0040, South Africa.
}

Accepted 16 November, 2012

\begin{abstract}
Credible governance of genetically modified organisms (GMOs) is essential because of public concerns in South Africa (SA) and internationally. In this preliminary study, the opinions of a number of scientists with experience and/or interest in GMO governance were determined by means of two questionnaires to determine their perceptions on the credibility of risk governance of GMOs in SA. The respondents felt 'some improvement' was required in criteria related to good governance. Excellence (quality of risk assessment) and effectiveness, such as protracted regulatory processes needed 'some to much improvement'. The responses were evaluated against an analysis of the South African GMO Act, regulations, policy guidelines and available information. The Act provides a pro-active basis for good governance comparable to internationally described risk governance models, but implementation seemed to follow the less advanced technocratic model. A number of reasons were identified such as unclear roles of decision makers. Some of the causes for protracted decision-making identified by respondents were: a) excessive precaution in decision making, and b) different mandates resulting in no unanimity among government departments. Proposals for improvement in credibility included communication as a critical component of risk governance and continued training of reviewers and decision makers.
\end{abstract}

Key words: Genetically modified organisms, risk assessment, risk governance, South Africa.

\section{INTRODUCTION}

A recent study, confirming the need for further investigation of the South Africa's (SA) risk governance of genetically modified organisms (GMOs) (Jaffe, 2008),

${ }^{*}$ Corresponding author. E-mail: kobus.eloff@up.ac.za. Tel: 27(0)836270089.

Abbreviations: AC, GMO Advisory Committee; CAC or Codex, Codex Alimentarius Commission; DAFF, Department of Agriculture, Fisheries and Forestry; DEA, Department of Environmental Affairs; DOH, Department of Health; DST, Department of Science and Technology; the DTI, the Department of Trade and Industry; EC, GMO Executive Committee. points to various deficiencies in governance that could impact on credibility and could cause delays in processing of permits, resulting in increasing costs of registering new GMO products. Incidents that raised concern to ensure that risks are addressed in a scientific way (Paarlberg, 2000) and that illustrated conflicting approaches between departments that could affect credibility, were (DAFF, http://www.daff.gov.za):

a) protracted decision making such as the embargo on commodity clearances (import of GM grains) since 2005 until 2011(DAFF, http://www.daff.gov.za); b) delays in stacked trait cotton approvals and several appeals against decisions (DAFF, http://www.daff.gov.za); c) poorly justified socio-economic reasons for refusal of permits (DAFF, http://www.daff.gov.za); and, d) the 
Department of Trade and Industry's (the DTI) mandatory requirement for labelling of genetically modified ingredients and components (not defined) in the Consumer Protection Act (South Africa, 2008) to enable consumer food choices, despite existing labelling regulations by the Department of Health (DOH) (South Africa, 1972; 2004).

The current study addressed the question: How credible is governance of GMOs in SA as perceived by scientists with knowledge of the system?

Much has been said on improvement of trust in governance in general, such as the need for more transparency in decision making (FAO/WHO, 2006). Health hazards such as the bovine spongiform encephalitis (BSE), a transmissible, neurodegenerative, fatal brain disease of cattle, and debates on food GMOs in Europe resulted in changes in government food safety systems (Dreyer et al., 2006; Atkins and Norman, 2009). The establishment of the European Food Safety Authority (EFSA) in 2002 as an independent and transparent organization to advise the Commission of the European Communities on food safety was one of the major reforms in Europe to restore public trust (CEC, 2002).

The concept of risk governance has received considerable attention lately (Dreyer et al., 2006, Dreyer and Renn, 2009; CAC, 2010). The Codex Alimentarius Commission (CAC), an International Commission addressing food standards, has pro-actively described the process of risk analysis (risk assessment, risk management and risk communication) and the principles that could be applied by governments to improve open and transparent decision making (CAC, 2010). A comprehensive scope of food safety/risk governance that could equally be applied to environmental safety/risks has been defined as: the totality of actors, rules, conventions, processes and mechanisms concerned with how relevant food risk information is collected, analysed and communicated, and decisions on food safety management are made.

Food risk governance includes, but extends beyond the three components of risk analysis (risk assessment, risk management, risk communication). It also involves coordination between public bodies, commercial and civil society actors, and wider contextual factors such as institutional arrangements, legislative procedures and political culture (Dreyer, et al., 2006).

Millstone (2007) identified three successive models of governance as a) technocratic, b) decisionist, and c) coevolutionary, demonstrating increasing interaction with stakeholders and including matters of socio-economic importance. In technocratic governance models, the roles of risk assessors and risk managers (decision makers) are not well separated. This is found in older governance structures and may result in poor decisions, such as the BSE scandal in the United Kingdom (Dreyer et al., 2006).

The decisionist model strongly favours functional separation (Millstone, 2007). The CAC supports functional separation to ensure the scientific integrity of the the risk assessment, to avoid confusion over the functions to be performed by risk assessor and risk managers and to reduce conflict of interest' (CAC, 2011).

The co-evolutionary or democratic model (transparent model according to Renn (2008), includes additional structured reciprocal links between science (risk assessment) and policy (risk assessment framing, management and decision making) as well as an evaluation step to evaluate risks versus benefits (Morris, 2011). This requires stakeholder participation (Millstone, 2007; Dreyer et al., 2009). Presently, more research is being conducted on the concept of participation. The role of democratic decision making depends on 'opening up the governance process' (Stirling et al., 2009). Consultation can occur through advisory committees, ad hoc consultations public hearings and regulatory instruments. The Commission of the European Communities (CEC) identified the following criteria of good governance: independency in risk assessment, ethical conduct, transparency, openness, participation, accountability, excellence in conduct and effectiveness (CEC, 2000, 2001). Models of good governance were used to compare development of SA governance of GMOs with international examples of GMO governance.

The SA GMO Act (South Africa, 1997) legislates all GMOs including GM seed and grain, GM microorganisms and GM animals. All activities are included from importation, contained use, trials, general release, monitoring and exportation. The SA area planted according to 2011 statistics (James, 2011) are a combined 2.3 million hectares of GM maize, GM soybean and GM cotton (maize $72 \%$ or 1.873 million hectares of total maize planted; soybean $85 \%$ or 1,873 million hectares of total; cotton $100 \%$ or 15000 hectares). No microorganisms or GM animals have been approved for general release. GM vaccines are only in clinical trials.

In SA, the GMO Act (Act 15 of 1997) is often held as an example for future food safety governance models (Chanda et al., 2010). This model partly resembles the framework for risk governance in Europe. With the exception of the labelling of GMO foods, governance in the SA of GMOs is legislated in terms of the GMO Act as amended (South Africa, 1997) and administered by the Department of Agriculture, Forestry and Fisheries (DAFF). The Act establishes a decision making body, the GMO Executive Council (EC), constituted in practice of one representative from each of six government departments plus the chairperson of the GMO Advisory Committee (AC). The government departments have mandates in terms of their own legislation except for Department of Science and Technology (DST) whose mandate also derives from the National Biotechnology Strategy for South Africa (South Africa, 2001). DOH reactively regulates the safety of food (South Africa, 1972). The Department of Environmental Affairs (DEA) has additional responsibility for environmental safety of 
GMOs in terms of the National Environmental Management: Biodiversity Act (South Africa, 2004). The AC consists of independent scientists from academia, research institutes and the private sector, and submits recommendations on permit applications to the EC.

The risk assessment step in risk governance is of necessity and partly non-transparent because of the confidentiality of certain company information. Government policy may reduce transparency. This was exemplified by the fact that the EC discouraged government GMO regulatory scientists from responding to the survey described in this paper, by stipulating that these scientists must first obtain written ministerial approval.

Therefore, determination of credibility could not be based on first-hand information but only on perce-ptions by those who viewed the system from outside. These perceptions do however, indicate problem areas. This study should be regarded as preliminary because policy makers and scientists directly involved in the regulatory process were not allowed to participate.

\section{MATERIALS AND METHODS}

The study includes an analysis of applicable legislation, analysis of available official guidelines, interviews with the SA government officials and two questionnaires distributed to the SA scientists with knowledge of GMO legislation and risk assessments. The first questionnaire, targeting a limited number of scientists from industry, public research and academic institutes, was designed to: a) qualitatively describe a credibility profile of the SA governance of GMOs from responses to criteria and sub-criteria described in Table $1 \mathrm{a}, \mathrm{b})$ probe perspectives in general on criteria of good governance based on the statements in Table 1b. These statements and results were grouped under three categories of good governance, namely policies/procedures (statements 10.1 to 10.15), excellence scientific (statements 11.1 to 11.8 ) and transparency (statements 12.1 to 12.9).

For the first questionnaire, 24 responses (response rate of $10.2 \%$ including possible responses from regulatory authorities and members of the AC) were obtained and considered as a fair number in this field, considering the constraints encountered. The low response rate could be ascribed to: i) Some potential respondents were unfamiliar with the subject; ii) Government officials as well as advisors to government (a possible 54 responses) did not participate and neither did anti- GM lobby groups; iii) in a number of cases, a single response was received per biotechnology seed company or a research institute, instead of responses from individual persons and iv) The internet approach for questionnaires presented several technical problems.

The participants could be considered as a homogenous group, representing applicants or potential applicants for permits and having in common marketing (or general release) of GMO products or an academic interest.

Statements in the three categories of good governance of the questionnaire indicate a reasonable general understanding of 'good governance' among respondents. Although the response numbers were relatively low, valuable information was obtained that should lead to a more in-depth future study of risk governance. The current study focused on assessment of priority needs to improve legislation, policy and implementation.

In a second questionnaire, a few key scientists from the agricultural biotech seed industry in the SA and scientists responsi- ble for preparation of permit applications were questioned regarding their views on reasons for delays in issuing of permits and proposed remedial actions (Figure $2 \mathrm{a}, \mathrm{b}$ ). Six responses were obtained. The participants were existing or potential permit-holders who had submitted new applications in the last five years. Importers of GM grain were not included as they were not directly involved in new submissions. They were also involved in a legal dispute with government at the time of the study.

\section{RESULTS AND DISCUSSION}

The majority view of the scientists was that some improvements were required to ensure credible governance. In particular, results to responses 'transparency', 'openness', legislation' and 'participation' needed 'some improvement'. 'Effectiveness', 'excellence' 'scientific' and 'accountability'needed 'some to much improvement', whereas, 'ethical'conduct and 'independency' in risk assessments needed 'no to some improvement' (Figure 1). The results are discussed in more detail in terms of three categories that underpin credible risk governance: i) functional separation between risk assessment and risk management (policies and procedures); ii) excellence in performance (risk assessors and reviewers, review procedures); and iii) transparency in governance (communication, participation).

\section{Functional separation between risk assessment and risk management}

The legal framework for governance of GMOs in the SA provides for functional separation between risk assessment and risk management (South Africa, 1997). This brings the SA in line with Codex guidelines (CAC, 2011) but also with the most developed examples of independency in risk governance such as the EFSA (EFSA, http://www.efsa.europa.eu).

Almost all responding SA scientists agreed on the importance of separate roles for the EC (Table 1b, 10.5) and AC (Table 1b, 10.3), but felt that some improvement was needed in clarifying those roles (Figure 1, Table 1a, 3 ). The statement 'EC members do not have a role as reviewers of risk assessment data/information' (Table 1b, $10.4)$, created some disagreement $(21 \%$ disagree, $67 \%$ agree, $12 \%$ unsure). Some felt that government by virtue of its own legislation has a responsibility to conduct independent reviews. This is indeed the case with proactive SA environmental legislation (South Africa, 2004) and is now also included in the amendment to the GMO Act (South Africa, 1997). One respondent felt that 'the legislation needs some work; the DEA calls for 'coordinated regulations of GMOs, but undertakes its own risk assessments'. The respondent suggested: 'the AC ...will undertake a complete risk assessment of all safety issues. The EC members must address non-safety issues, such as cultural impact, loss of traditional knowledge, impact on trade and labour etc.' 
Table 1a. South African GMO risk governance: Scores for credibility criteria and sub-criteria.

\begin{tabular}{|c|c|c|c|c|c|c|}
\hline Criteria & Sub-criteria & NI & SI & MI & DNK & Total \\
\hline 1. Legislation & & 4 & 11 & 3 & 1 & 19 \\
\hline 1.1 & Following the latest international model of risk analysis & 4 & 12 & 3 & 3 & \\
\hline 2. Effectiveness & & 0 & 10 & 8 & 1 & 19 \\
\hline 2.1 & Clear roles in the legislative processes & 7 & 11 & 5 & 1 & \\
\hline 2.2 & Evaluation of future impact & 2 & 13 & 7 & 2 & \\
\hline 2.3 & Past experience, where possible & 3 & 14 & 4 & 3 & \\
\hline 2.4 & Clear guidelines & 3 & 13 & 7 & 1 & \\
\hline 3. Accountability & & 3 & 8 & 6 & 3 & 20 \\
\hline 3.1 & Clear roles in the legislative processes & 4 & 12 & 4 & 3 & \\
\hline 3.2 & Clear roles in the executive processes & 3 & 12 & 5 & 3 & \\
\hline 3.3 & Clear roles for risk assessors & 4 & 10 & 5 & 3 & \\
\hline 3.4 & Parties to assume responsibility for their roles & 1 & 8 & 9 & 5 & \\
\hline 4. Independency & & 7 & 4 & 4 & 4 & 19 \\
\hline 4.1 & No pressure on risk assessors from policy makers & 10 & 5 & 3 & 5 & \\
\hline 4.2 & Risk assessors acceptable to all parties & 7 & 8 & 3 & 5 & \\
\hline 4.3 & No pressure from stakeholders on risk assessors & 9 & 7 & 3 & 4 & \\
\hline 5. Scientific excellence & & 2 & 9 & 7 & 1 & 19 \\
\hline 5.1 & Enough suitably qualified specialist risk assessors & 3 & 10 & 8 & 3 & \\
\hline 5.2 & Peer-reviewed assessments of scientific information & 4 & 13 & 4 & 3 & \\
\hline 5.3 & Best use of available information systems & 1 & 13 & 6 & 4 & \\
\hline 5.4 & Consulting with international organizations & 0 & 13 & 3 & 8 & \\
\hline 5.5 & Networking with national food safety authorities & 1 & 9 & 6 & 8 & \\
\hline 5.6 & Consulting with independent experts & 1 & 13 & 4 & 6 & \\
\hline 5.7 & Risk assessments: international standards/guidelines & 5 & 11 & 3 & 5 & \\
\hline 5.8 & SA accredited laboratories & 2 & 11 & 7 & 4 & \\
\hline 5.9 & International standards & 4 & 12 & 3 & 5 & \\
\hline 6. Ethical conduct & & 7 & 5 & 2 & 5 & 7 \\
\hline 6.1 & Risk assessors do not have a conflict of interest & 9 & 8 & 2 & 5 & \\
\hline 6.2 & Risk assessors have confidentiality clearance & 8 & 4 & 1 & 11 & \\
\hline 7. Openness & & 1 & 12 & 5 & 1 & 19 \\
\hline 7.1 & Interaction with stakeholders & 4 & 11 & 8 & 1 & \\
\hline 7.2 & Decision making & 3 & 8 & 12 & 1 & \\
\hline 8. Participation & & 3 & 10 & 4 & 2 & 19 \\
\hline 8.1 & Inclusive approach & 3 & 10 & 9 & 2 & \\
\hline 9. Transparency & & 1 & 12 & 5 & 1 & 19 \\
\hline 9.1 & Clear procedures & 3 & 16 & 4 & 1 & \\
\hline 9.2 & Communicating uncertainty in risk assessment & 2 & 10 & 8 & 4 & \\
\hline 9.3 & Risk assessors' names and qualifications known & 4 & 7 & 5 & 8 & \\
\hline
\end{tabular}

$\mathrm{NI}$ = No improvement; $\mathrm{SI}$ = some improvement; $\mathrm{MI}$ = much improvement; $\mathrm{DNK}=$ do not know

Independency as a criterion for credibility was regarded as important. The majority of respondents (92\%) agreed that risk assessment should be conducted independently from risk management (Table 1b, 10.2). Respondents also agreed that risk assessors were independent and not subject to pressure from policy makers or stakeholders. The members of the AC were acceptable to most respondents (Table 1a, 4). One area of future concern, though not identified by respondents to the questionnaire, is that the representation on the $A C$ in terms of the amended GMO Act may include two officials representing the 'public sector' --undefined (South Africa, 1997). Presumably, they could be from semi-state institutes or government departments. The concern is that government officials are bound by political policy and may not be regarded as independent.

A specific characteristic of 'independency' is that the risk assessment should be 'a purely scientific activity' $(C A C, 2011)$ and the majority of respondents agreed that this was the case (Table 1b, 10.1). This is the requirement in Section 3.3.a of the GMO Regulations which states that applicants must submit a 'scientificallybased risk assessment', again repeated in the heading of Section 4 (South Africa, 1997). Some sociologists contest this view as not completely possible, as risk assessors (or reviewers) would to some extent approach the assessment subjectively (Meghani, 2009). This argument is held in favour of more transparency in assessment of risks that need to be considered in new governance models.

Ethical conduct relates to the criterion 'independency from pressure of applicants' and includes 'confidential clearance' and lack of 'conflict of interest'. Some respondents were uncertain of the degree of lack of 
Table 1b. South African GMO risk governance: Scores for statements on credibility (\%) (AC, GMO Advisory Committee; EC, GMO Executive Council).

\begin{tabular}{|c|c|c|c|c|c|}
\hline Number & Statement & Total response & Agree & Disagree & Unsure \\
\hline 10 & Policies and Procedures & & & & \\
\hline 10.1 & $\begin{array}{l}\text { RISK ASSESSMENT of GMO's is deemed to be a purely } \\
\text { scientific activity }\end{array}$ & 24 & 84 & 16 & 0 \\
\hline 10.2 & $\begin{array}{l}\text { RISK ASSESSMENT should be conducted independently from } \\
\text { risk management (including from political influences) }\end{array}$ & 24 & 92 & 8 & 0 \\
\hline 10.3 & $\begin{array}{l}\text { The role of the AC is to review food/feed safety data of new } \\
\text { GMOs and make recommendations to the EC }\end{array}$ & 23 & 100 & 0 & 0 \\
\hline 10.4 & $\begin{array}{l}\text { EC members do not have a role as reviewer of risk assessment } \\
\text { data/information }\end{array}$ & 24 & 67 & 20 & 13 \\
\hline 10.5 & $\begin{array}{l}\text { The role of the risk managers, including the } E C \text {, is to consider } \\
\text { managerial risk options regarding risk assessments as proposed } \\
\text { by the AC }\end{array}$ & 24 & 92 & 4 & 4 \\
\hline 10.6 & $\begin{array}{l}\text { Any uncertainty / disagreement / need for more information } \\
\text { regarding scientific issues should be referred back to the AC for } \\
\text { advice before final decisions are made at EC level }\end{array}$ & 24 & 100 & 0 & 0 \\
\hline 10.7 & $\begin{array}{l}\text { The AC should be more pro-active by not only advising on } \\
\text { proposals for specific activities or projects but also make } \\
\text { proposals in this respect }\end{array}$ & 22 & 91 & 9 & 2 \\
\hline 10.8 & Lack of policies on some regulatory matters & 24 & 63 & 8 & 29 \\
\hline 10.9 & $\begin{array}{l}\text { The AC should initiate new policies pertaining to assessments, } \\
\text { e.g. , guidelines for risk } \\
\text { assessment requirements }\end{array}$ & 24 & 92 & 4 & 4 \\
\hline 10.10. & $\begin{array}{l}\text { The function of the AC should include the development of } \\
\text { guidelines for regulatory risk assessment requirements }\end{array}$ & 24 & 96 & 4 & 0 \\
\hline 10.11 & $\begin{array}{l}\text { Case-by-case assessments could result in uncertainty in } \\
\text { regulatory requirements }\end{array}$ & 24 & 50 & 46 & 4 \\
\hline 10.12 & $\begin{array}{l}\text { Guidelines for regulatory requirements of GM food and feed } \\
\text { safety should have more detail }\end{array}$ & 24 & 71 & 13 & 17 \\
\hline 10.13 & Too many separate application forms & 24 & 29 & 33 & 38 \\
\hline 10.14 & $\begin{array}{l}\text { An EVALUATION step to consider socio-economic effects and } \\
\text { benefits, should be included in the pre-regulatory assessment, } \\
\text { before the managerial decision making step }\end{array}$ & 24 & 75 & 17 & 8 \\
\hline 10.15 & $\begin{array}{l}\text { The AC should receive more legal status as an independent } \\
\text { advisory body }\end{array}$ & 24 & 42 & 25 & 33 \\
\hline 11 & Excellence & & & & \\
\hline 11.1 & Peer-reviewing of information is very important & 24 & 100 & 0 & 0 \\
\hline 11.2 & A single multi-disciplinarian cannot replace a team of specialists & 24 & 100 & 0 & 0 \\
\hline 11.3 & $\begin{array}{l}\text { Risk assessors should be involved in research to remain in touch } \\
\text { with science }\end{array}$ & 24 & 79 & 17 & 4 \\
\hline 11.4 & $\begin{array}{l}\text { The AC specialists should be included in the government team to } \\
\text { international meetings/conferences }\end{array}$ & 24 & 92 & 4 & 4 \\
\hline 11.5 & $\begin{array}{l}\text { South Africa should keep a roster of all details of potential risk } \\
\text { assessors for GMOs }\end{array}$ & 24 & 88 & 4 & 8 \\
\hline 11.6 & $\begin{array}{l}\text { PhD-degree qualification with at least } 3 \text { years experience in the } \\
\text { relevant discipline }\end{array}$ & 23 & 87 & 13 & 0 \\
\hline 11.7 & $\begin{array}{l}\text { MSc-degree qualification with at least } 5 \text { years experience in the } \\
\text { relevant discipline }\end{array}$ & 24 & 75 & 21 & 4 \\
\hline 11.8 & $\begin{array}{l}\text { To be nominated as a member of the AC, the specialist should } \\
\text { have conducted at least } 10 \mathrm{GM} \text { food/feed safety assessments }\end{array}$ & 23 & 39 & 39 & 22 \\
\hline 12 & Transparency & & & & \\
\hline 12.1 & $\begin{array}{l}\text { RISK ANALYSIS policies should be developed in collaboration } \\
\text { with stakeholders }\end{array}$ & 24 & 100 & 0 & 0 \\
\hline
\end{tabular}


Table 2. Contd.

\begin{tabular}{|c|c|c|c|c|c|}
\hline 12.2 & $\begin{array}{l}\text { Stakeholders communication in risk analysis of GMOs in } \\
\text { important }\end{array}$ & 24 & 100 & 0 & 0 \\
\hline 12.3 & $\begin{array}{l}\text { Stakeholder participation in the scientific reviewing of company } \\
\text { information is not acceptable }\end{array}$ & 24 & 42 & 29 & 29 \\
\hline 12.4 & $\begin{array}{l}\text { Stakeholder participation regarding the evaluation of the potential } \\
\text { risk in the context of socio-economic impact is invaluable }\end{array}$ & 24 & 71 & 17 & 12 \\
\hline 12.5 & $\begin{array}{l}\text { Commencement of risk assessment of new GMOs should be } \\
\text { announced in the media }\end{array}$ & 24 & 38 & 54 & 8 \\
\hline 12.6 & $\begin{array}{l}\text { The risk assessment report of the AC should be made available } \\
\text { to the applicant for comments to be considered by the EC }\end{array}$ & 24 & 92 & 8 & 0 \\
\hline 12.7 & $\begin{array}{l}\text { The risk assessment report of the AC should be published for } \\
\text { information }\end{array}$ & 24 & 62 & 25 & 13 \\
\hline 12.8 & $\begin{array}{l}\text { The final approved report of the EC, including risk analysis } \\
\text { decisions as well as socio-economic and benefit considerations, } \\
\text { should be published on the internet/media for public information }\end{array}$ & 24 & 75 & 17 & 8 \\
\hline 12.9 & $\begin{array}{l}\text { There should be an opportunity for objections/comments to } \\
\text { decisions of the GMO Council }\end{array}$ & 24 & 84 & 8 & 8 \\
\hline
\end{tabular}

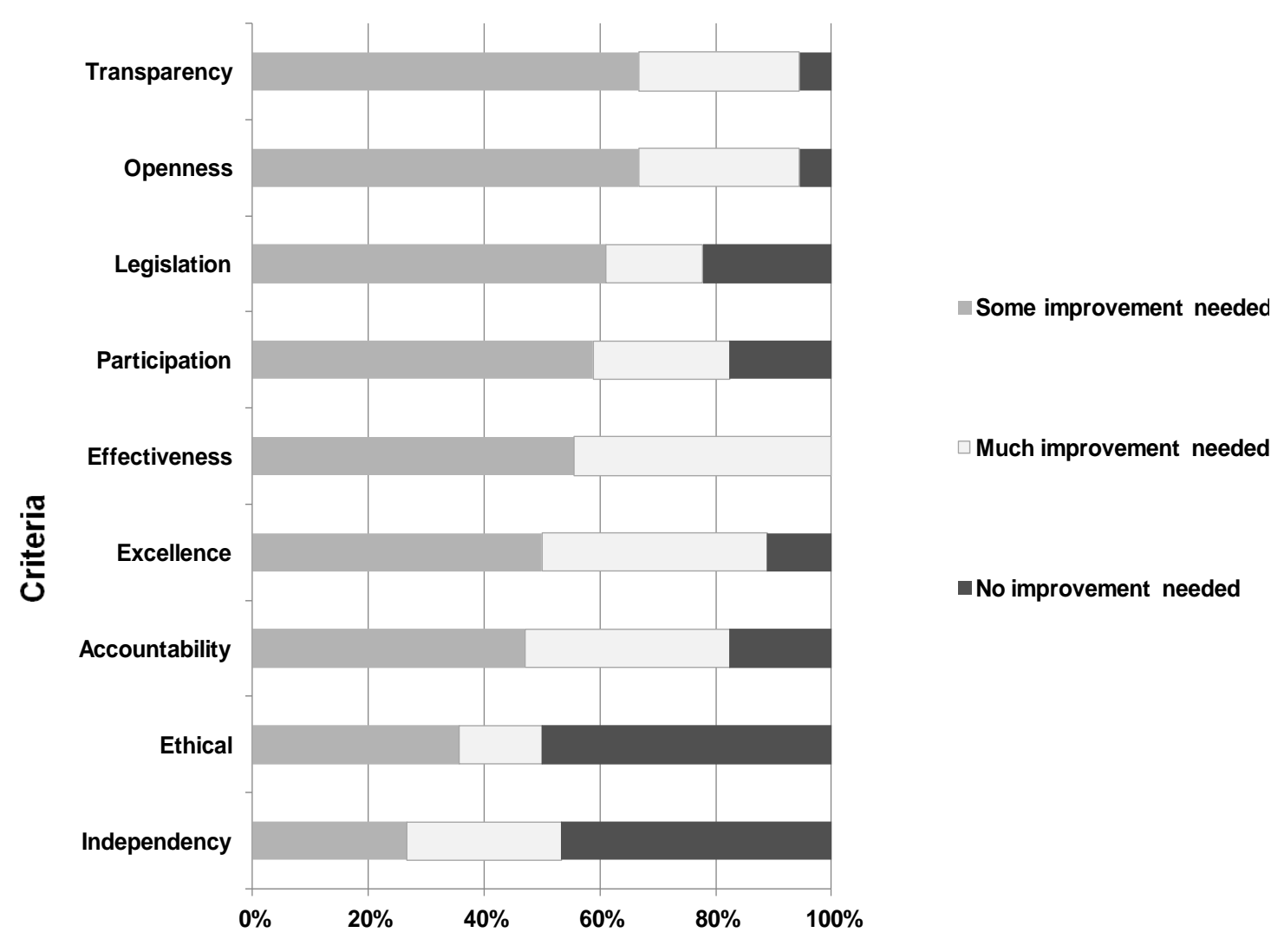

\section{Percentage}

Figure 1. Responses to status of GMO risk governance sorted on 'some improvement needed'.

conflict, probably because names of the sub-committee and most of the AC members were not publically available (Figure 1; Table 1a). One respondent remarked that it was impossible for scientists not to have vested interests.

The AC has a general advisory function but also speci- fic functions prescribed by the GMO AC (South Africa, 1997). Respondents gave strong support for specific functions in addition to reviewing of dossiers. These included advising on uncertainties and disagreements at EC level (Table 1b, 10.6, 100\%), being pro-active by pro- 


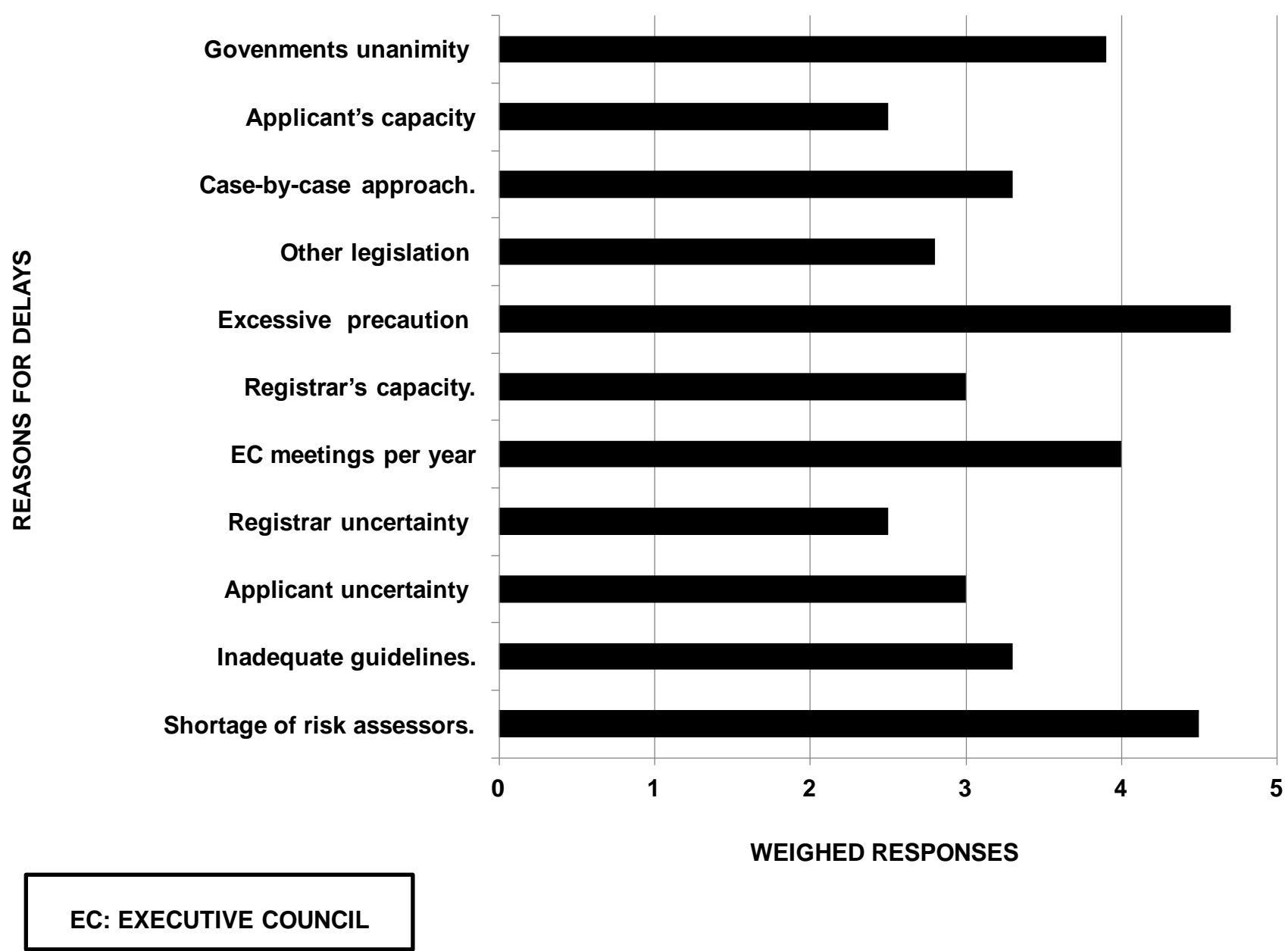

Figure 2a. Responses from the agricultural biotechnology industry / applicants on the reasons for delays in approval of GMO permits. (Weighed responses, ranking groups: 1 = unimportant to $5=$ extremely important).

proposing specific activities and projects (Table 1b, 10.7, $91 \%$ ), and initiating new policies pertaining to assessments such as guidelines (Table 1b, 10.9, 92\%). Such pro-activity exists in the self-tasking functions of EFSA, (http://www.efsa.europa.eu). Availability of competent scientists could be a limiting factor for members of the AC as they are mostly employed full-time by universities or research institutes and though appointment to the $A C$ is a prestigious position, their available time is limited. There seems to be a need for more risk assessors (reviewers) (Figure 2a).

Respondents highlighted the need for improved effectiveness in the regulatory system. Only a few procedures were touched on in this study e.g. managerial responsibility such as planning (Table $1 \mathrm{a}, 2$ ) and decision making (Table 1b, 10). Effectiveness was reflected by the time taken to reach a decision on the issuing of a permit; approvals for commodity clearances were delayed from 2005 until 2011. A number of reasons for delays were given (Table 2a). There seemed to be inconsistency in requests for more information from different panels or similar information repeatedly requested, and requests for additional information not requested before. Excessive precaution in decision making, shortage of risk assessors, infrequent EC meetings, no unanimity between government departments on national policy; and inadequate guidelines were cited as main causes. This study did not consider for example the need for improvement of quality of dossiers and more training of applicants as often experienced in regulatory situations by one of us as a former regulator. An example of poor quality and incompleteness of a dossier was the case of a banana application (ACB, 2011). Effectiveness of the regulatory system needs addressing in much detail.

\section{Scientific excellence}

The quality of risk assessments appeared to require substantial improvement (Table 1a, 5). Codex guidelines were generally followed and the opinion was that international guidelines were being adhered to (Table $1 \mathrm{a}$, $5.7,5.9)$. It is possible to conclude that a reviewer with 


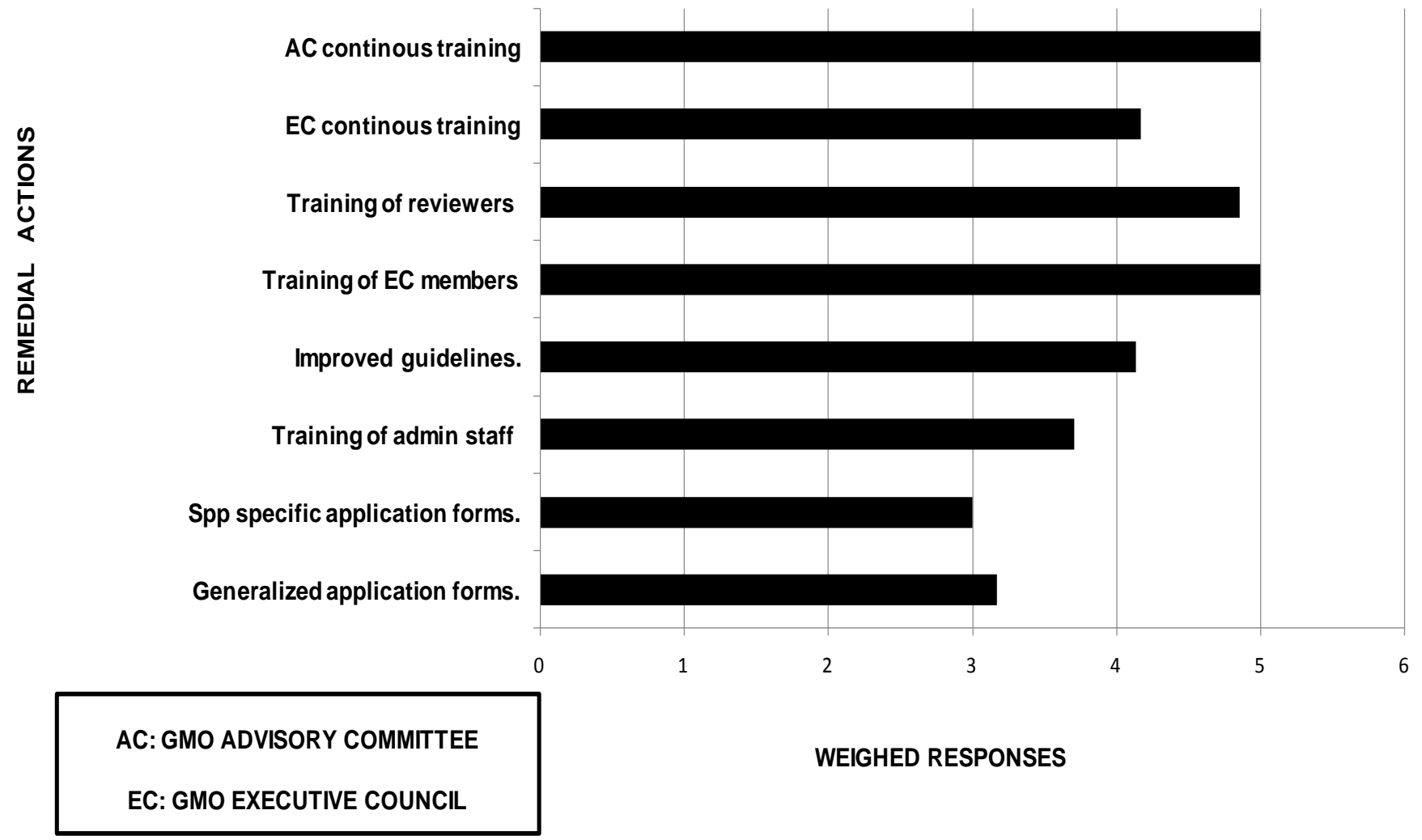

Figure 2b. Respondents from agricultural biotechnology industries/applicants on proposed remedial actions for delays in GMO permit approvals. (Weighed responses from ranking groups: $1=$ unimportant to $5=$ extremely important).

less experience tends to request much more additional information than an experienced reviewer. Reviewers undertake their tasks independently and therefore may form a variety of opinions. There is little opportunity for reviewers to discuss amongst themselves or for inexperienced reviewers to learn from their more experienced colleagues. In these circumstances, Codex guidelines may also be interpreted differently by different reviewers. It is also unclear what approaches to risk assessments are followed, the comparative risk analysis approach (CAC, 2009; Kuiper et al., 2001) or a toxicological risk assessment (Millstone et al., 1999). Excessive caution in decision making was identified as the main reason for delays in approvals (Figure 2a). Training of risk assessors (reviewers) and decision makers was considered as an important remedial action (Figure 2b).

All respondents agreed on the importance of peer review of risk assessment reports (Table 1b, 11.1) and that a single multi-disciplinarian could not replace a team of specialists (Table 1b, 11.2). The current procedure (South Africa, 2008) is to appoint, on a case-by-case basis, a panel of three reviewers from the $A C$ subcommittee with a member of the $A C$ as chairperson. Each reviewer's report and recommendations are included in a final report to the EC. Additional information may be requested from the applicant by the reviewers. It is not clear from the Guidelines (South Africa, 2008; DAFF, http://www.daff.gov.za) whether the full AC meeting would discuss or review the final report. The procedure seems to emphasize 'reporting' rather than 'reviewing'. The EC would consider the AC reports, public inputs, as well as reviews from the different government departments. This transferred final reviewing to the EC rather than the AC level. The current procedure reduces time taken for finalizing initial reviews but could also lead to inconsistent recommendations and requests for more information, causing delays, as identified in the second questionnaire (Table 2a). Adequacy of expertise within small panels to cover a number of disciplines such as both food and environmental issues in general release permits, may be a constraint. These aspects may be too broad for the small panel to cover although additional expertise could be co-opted. An option would be to conduct peer reviewing at the level of the full $A C$ meeting where a greater diversity of expertise is present. Another option would be to conduct reviewing by focused subpanels. Against this approach, one respondent remarked that 'there is also a need for overall multi-disciplinary understanding as opposed to over-specialized'. Peer reviewing needs to be critically investigated for optimization of this process.

Respondents agreed that a PhD-degree with at least three years of experience or an MSc-degree with at least 
five years of experience in relevant disciplines seemed adequate for eligibility for the AC. There was no consensus on any particular number of reviews that should have been handled before being nominated (Table 1b,11.6 to 11.8). Countries such as Brazil require a PhD-degree as a minimum qualification. That may not be a practical suggestion because of lack of capacity at this stage in SA.

The respondents identified the lack of sufficient adequately trained risk assessors as a problem (Table 1b, 5.1; Figure. 2a). One reason could be the poor remuneration which is considerably lower than that stipulated in the guidelines of the South African Council for Natural Scientific Professions (South Africa, 2003). Reasons could also include exposure to criticism or lack of interest or inadequate time allocated. Respondents recommended that a detailed roster of potential risk assessors should be kept (Table 1b, 11.5). Such a roster of expertise is a requirement of the Biosafety Clearing House $(\mathrm{BCH}$,$) established under the Cartagena Protocol$ on Biosafety to the Convention on Biological Diversity (CPB, http://www.cbd.int/biosafety/protocol.shtml). At present, no experts from SA are listed on the $\mathrm{BCH}$ website, despite many names having been submitted, making it difficult to source expertise. In addition, the latest Protocol records show that the Ministry of Environmental Affairs is the national focal point with only one communication record received, both this department and the Ministry of Agriculture are listed as competent authorities, and four records and 13 decisions (permit approvals) received from DAFF, though more than 350 permits are granted annually (DAFF, http://www.daff.gov.za). DAFF's clearing house link seems to be inoperative at times.

As a remedial option to address delays, respondents agreed on the need for AC members to have continued exposure to new information, to attend international meetings and conferences, and to be involved in research and new developments in relevant disciplines including risk assessment approaches (Table 1b, 11.3 and 11.4). Training of $E C$ and $A C$ members was regarded as essential to help reduce delays in the regulatory process (Figure $2 b$ ).

One respondent felt that assessors (reviewers) also needed 'contact and input from industry experts and practices'. Industry, especially the multi-national industry, has the means to employ world class specialists to conduct research in specialized areas'. Knowledge and experience of scientists from the industry may be considered in specific cases according to the Food and Agricultural Organization and World Health Organization's expert group (FAO/WHO) (2006).

International outreach programmes often focus only on regulatory authorities unless the need of risk assessors (reviewers) is brought to their attention. Where skills and experience are scarce, capturing of institutional memory collectively is important. This has not been well exploited in the SA risk analysis framework. Coordination in this respect is important. The majority of respondents felt that scientists who were members of the AC should be included in government delegations to international meetings/conferences. There seemed to be a general awareness of the importance of access to international scientific exposure and the need for improvement in this regard (Table 2a, 5.3 to 5.5). In a strategic review of Food Standards Australia New Zealand (FSANZ, 20032004), it was stated that credibility 'was founded on the quality of its science and its scientific risk assessments'. One of the recommendations was that the FSANZ continued to forge strong linkages with international experts and other regulatory agencies. FAO/WHO (2006) confirmed continuous exposure to international developments was important.

\section{Transparency}

The majority of respondents rated transparency as needing some improvement. The questionnaire tested a few pertinent issues, namely clear procedures; communication of uncertainty; and identification of the risk assessors (Table 1a, 9.1-3). The need was identified for some improvement in all three areas. Procedures, guidelines, application forms, and permits are adequately published on the website of the DAFF, but there appears to be a lack of transparency in EC decision making. The minutes of the EC meetings are too cryptic, suffer delayed listing and risk assessment recommendations are not available. The Promotion of Access to Information Act (South Africa, 2000a) that aims to 'foster a culture of transparency and accountability', provides at a nominal fee a legal opportunity to demand additional information. Compared with the extent of accessibility of reports in Australia (FSANZ, http://www.foodstandards.gov.au; http://www.ogtr.gov.au) and EFSA (EFSA 2006, 2009), the $S A$ website information (DAFF, http://www.daff.gov.za) has limitations.

\section{Participation}

The majority of respondents agreed that stakeholder participation regarding the evaluation of the potential risk in the context of socio-economic impact was invaluable (Table 1b, 12.4). Participatory procedures are not new to the SA decision making but represent a new concept in the risk analysis process. In general, respondents indicated that significant improvement was needed for participation in the SA system, including participation in policy development and risk assessment (Table1a, 8). All respondents agreed that risk analysis policies should be developed in collaboration with stakeholders (Table 1b, 12.1) and that communication was important (Table $1 \mathrm{~b}$, 12.2). Opportunity for public input is included in the GMO 
Act (South Africa, 1997) and should be exploited in a structured way.

In line with Article 26 of the Cartagena Protocol on Biosafety (Secretariat of the Convention on Biological Diversity, 2000), the GMO Act includes provision for socio-economic assessment as part of the risk analysis. This may include cost-benefit and risk-benefit comparisons but Section 5.1 in the regulations is extremely vague on required, but undefined consideration of the socio-economic impact on biodiversity, access to natural resources, cultural traditions, knowledge, and practices. The majority $(75 \%)$ of respondents agreed that socioeconomic analysis should take place prior to decision making (Table 1b, 10.14). At this point, 'opening up the governance process through public participation' (CEC, 2000) would be important. Stakeholders may contribute to 'democratic' decisions of the risk managers at some stage in the process. One respondent stated that, 'nonsafety issues should be considered by the EC (mandate to review) and not the AC (focus on safety and science). Non-safety issues are relevant only to general release, not to contained or confined activities, which are experimental and short term'. Another respondent commented that 'socio-economic effects should have a minor influence on risk decisions'. Although socioeconomic issues may be addressed as a requirement of the GMO Act (South Africa, 1997), little information regarding the procedures and requirements for socioeconomic analysis is available.

\section{Limitations of the study}

(1) Statistical analysis of the survey, althoughthe ideal means of analysis, is not possible with small target groups. This is unfortunately the case with a very specialized field such as risk governance of GMOs in a country with limited resources. In an almost similar study by Wentholt et al., (2009) on the risk analysis of GMOs, only 33 out of 106 invited European respondents participated and 19 out of 60 international non-EU participants. They were from a range of professions and occupations. Government officials with intimate knowledge of the system would most likely not be inclined to participate. Their opinion, should they be officially requested, would most likely not be spontaneous. However, their experience in the process of risk assessment is of great importance to identify needs of applicants.

(2) One deficiency identified in the study, is that we did not obtain the opinion of regulators on the quality of applications and provision of required information.

(3) The responses should largely be considered as 'perceptions'. Experience of the respondents are real, perceived, or from hearsay. Perceptions are valid observations that can be changed by improving the system and need be taken into consideration in partici- pative policy development, particularly on sociological matters.

(4) This study illustrates the opinions of some stakeholders at the time of the study. This may change with time for the same group. A group (different segment of the population) with priorities other than marketing of their products may have a different perception of credibility.

Consumers, in general, are not familiar with the technical side of regulatory matters and, therefore, a more simplified questionnaire will have to be designed for them.

(5) The study should be considered as preliminary as a more balanced opinion would include the experience of those intimately involved in SA risk governance of GMOs according to the mentioned criteria. They should include regulatory authorities, advisors to government as well as members of the AC.

\section{Conclusion}

This study tried to determine: How credible is governance of GMOs in SA as perceived by scientists with knowledge of the system?"

In general, respondents felt that 'some to much' improvement is necessary to ensure credibility. An analysis of the GMO Act, policy guidelines and delays in issuing of permits, as well as available information on the implementation of the Act, confirmed the perceptions. Based on these results, an indication is given where improvements are most needed to increase credibility of the system.

Although functional separation of risk assessment (AC) and decision making (EC) has been established in the SA legislation, the scope of decision makers' responsibilities needs be clearly defined as it seems as if the EC still functions according to intentions of the 'technocratic' model that may over-ride recommendations by the advisory body. This could cause increase in the workload and may be outside the expertise and mandate of some EC members, resulting in further delays in decision making.

A clearly identified deficiency was excellence in performance. This implied the need for improved review processes, and elimination of delays. The degree to which potential poor preparation of application forms contributed to delays could not be assessed due to lack of participation by regulators. Continued constructive exposure to new information, research and/or development as well as training of both decision makers and risk assessors were identified as priorities. Improved guidelines that address new challenges such as assessment of stacked traits need urgent attention.

Many aspects of transparency really need some improvement. 'Participation', in particular, as a democratic principle, has not yet been clearly developed 
in the SA governance of GMOs. This includes the contribution of stakeholders and scientists to framing of the assessments. Framing includes scientific inputs, policy development on various matters such as scientific approaches to risk assessments and socio-economic impacts and cultural considerations. New research on how to address participation by stakeholders at different stages of risk analysis needs attention.

Government has to consider development of integrated strategies and policies for good governance to achieve greater credibility of risk assessment of GMOs, not only of the risk assessment component itself, but also for all other components of governance. These should include:

(1) Harmonization between government departments in the approach to risk analysis, taking into account the National Strategy for Biotechnology for SA(South Africa, 2001) and including policy issues such as the approach to precaution.

(2) Policy on training, recruitment and remuneration of risk assessors (South Africa. 2003).

(3) An additional step could be consideredin the iterative process of risk analysis as described by Codex Alimentarius Commission for development of risk assessment policy that could give direction according to national strategy and good governance policies.

(4) The majority of the criteria of good governance could be grouped as communication related, transparency, participation, and openness. Therefore, improved communication is critical.

Although the credibility of the SA governance of GMOs could be improved, it has certain strengths that could be applied to other risk analysis systems. Functional separation of the risk assessment and decision making as contained in GMO legislation could be followed as an example to ensure scientific integrity; however, implementation of new legislation with respect to risk assessment such as for pesticides, should be critically considered with the necessary awareness of good risk governance to ensure credibility of decisions.

The availability of experienced risk assessors is a limiting factor in credible governance. The use of regional or subregional independent experts could be considered while in the meantime, educating and training of local candidate risk assessors should be a priority.

In general, the robustness of the governance of GMOs is reflected in the track record of safety since 1990, as no significant impact from accidents or adverse effects on humans or animals have been recorded. Trust and confidence will depend largely on the introduction of more democratic governance for both GMOs and other food safety matters.

\section{ACKNOWLEDGEMENTS}

We thank The National Research Foundation for providing funds, The Department of Statistics, University of Pretoria, a private biometrics consultant, Marie Smith, for the advice on statistical analysis and Cora Bezuidenhout for the reference management. We also wish to thank the respondents who shared their knowledge and perceptions with us and the reviewers of this manuscript.

\section{REFERENCES}

ACB - African Centre for Biosafety (2011).GM banana slips in South Africa: key issues and concerns.http://www.acbio.org.za/images/stories/dmdocuments/GMbanabas.pdf. Downloaded April 2012.

Atkins D, Norman JA (2009). A risk management perspective on the governance framework, in Food Safety Governance: integrating science, precaution and public involvement, Springer-Verlag: 207238. See also UK-FSA -United Kingdom, Food Standards Agency (2006). FSA chief scientist annual report.www.food.gov.uk. Downloaded April 2012.

$\mathrm{BCH} \quad$ - $\quad$ Biosafety $\quad$ Clearing House.http://www.cbd.int/biosafety/protocol/shtml. Downloaded March 2010.

CAC - Codex Alimentarius Commission (2011).Procedural manual.20 ${ }^{\text {th }}$ ed. Secretariat of the Codex Alimentarius Commission. Joint FAO/WHO Food Standards Programme. Rome: 105113.http://www.codexalimentarius.org/proceduresstrategies/procedural-manual/en/. Downloaded May 2012.

CAC - Codex Alimentarius Commission) (2009). Foods derived from modern biotechnology. Guideline for the conduct of food safety assessment of foods derived from recombinant DNA plants, CAC/GL 45-2003 as amended in 2008, FAO/WHO Food Standards Programme. $2^{\text {nd }}$

Rome.ftp://ftp.fao.org/docrep/fao/011/a1554e/a1554e00.pdf. Downloaded May 2012.

CEC - Commission of the European Communities (2001). European governance: a white paper. COM (2001): 428. http://ec.europa.eu/governance/white_paper/en.pdf. Downloaded March 2010.

CEC - Commission of the European Communities (2000). White paper on food safety.COM(1999): 719 http://ec.europa.eu/dgs/health_consumer/library/pub/pub06_en.pdf. Downloaded March 2010.

CEC - Commission of the European Communities (2002). Laying down the general principles and requirements of food law, establishing the European Food Safety Authority and laying down procedures in matters of food safety.Regulation (EC) No 178/2002 of the European Parliament and the Council, 28 January 2002, OJEC.L31(1): 1-24.

Chanda R, Fincham R, Venter P (2010). A review of the South African food control system: Challenges of fragmentation. Food Contrl. 21(6):816-824.

DAFF (2006-2012). Minutes of the GMO Executive Council.South African Department of Agriculture, Forestry and Fisheries, Pretoria.http://www.daff.gov.za. Downloaded May 2012.

DAFF (2008).Guideline document for subcommittees to assist the advisory committee in terms of Section 11(2) of the Genetically Modified Organisms Act of 1997.http://www.daff.agric.za. Downloaded April 2012.

Dreyer M, Renn O (2009). Food safety governance: integrating science, precaution and public involvement, Springer Verlag:3-245.

Dreyer M, Renn O, Borkhart K, Ortleb J (2006). Institutional rearrangements in European food safety governance: a comparative analysis, in Food Safety Regulation in Europe: A Comparative Institutional Analysis, Series lus Commune, Intersentia Publishing, Antwerp. pp. 9-64.

EFSA - European Food Safety Authority (2006). Transparency in risk assessment carried out by EFSA: guidance document on procedural aspects. EFSA J. 353:1-16.

EFSA - European Food Safety Authority (2009).Transparency in risk assessment - scientific aspects. Guidance of the Scientific Committee 
on transparency in the scientific aspects of risk assessment carried out by EFSA, pt 2: General principles. EFSA J. 1051:1-22.

EFSA - European Food Safety Authority.http://www.efsa.europa.eu. Downloaded April 2012.

EU - European Union (2004). European Union $6^{\text {th }}$ Framework Project: SAFE FOODS.http://www.safefoods.wur.nl. Downloaded April 2012.

FAO/WHO - Food and Agricultural Organization and World Health Organization of the United Nations (2006). Food safety risk analysis: a guide for national food safety authorities, FAO Nutrition paper no. 87, Rome.

FSANZ - Food Safety Australia New-Zealand (2003-2004). Annual report and FSANZ Science strategy.http://www.foodstandards.gov.au/scienceand_education /.D ownloaded April 2012. See also Bansemer A (2003). Food standards Australia New Zealand, a strategic review.http://www.foodstandards.gov.au/aboutus/strategicreview.cfm. Downloaded February 2005.

Jaffe G (2008). Ensuring Biosafety at the National Level: Suggestions to Improve the Operation of the South African Biosafety Regulatory System, Brief number 11, PBS, Intl Food Policy Inst. http://www.ifpri.org/publication/ensuring-biosafety-national-level. Downloaded March 2010.

James C (2011) Global status of commercialised biotech/GM crops: 2011. ISAAA Brief number 43, ISAAA: Ithaca, NY: 129-35.

Kuiper HA, Kleter GA, Noteborn HPJM, Kok EJ (2001). Assessment of the food safety issues related to genetically modified foods. Plant $\mathrm{J}$, 27(6):503-528.

Meghani Z (2009). The US Food and Drug Administration, Normativity of risk assessment, GMOs and American democracy. J. Agr. Environ. Ethic.22: 125-139.

Millstone E (2007). Can food safety policy-making be both scientifically and democratically legitimated? If so, how? J. Agr. Environ. Ethic. 20(5): 483-508.

Millstone E, Brunner E, Mayer S (1999). Beyond substantial equivalence.Nature.401(6753): 525-526.

Millstone $E$, van Zwanenberg $P$, Levidow L, Spök A, Hirakawa $H$, Matsuo M (2008).Risk-assessment policies: differences across jurisdictions, EUR 23259 EN. Joint Research Centre, European Commission. http://publications.jrc.ec.europe.eu/. Downloaded March 2010.

Morris EJ (2011). A semi-quantitative approach to GMO risk-benefit analysis. Transgenic Res. 20:1055-1071.

OGTR - Office of the Gene Technology Regulator, Department of Health and Ageing, Australia. http://www.ogtr.gov.au. Downloaded April 2012. See also FSANZ.

Paarlberg RL, Gruhn P, Goletti F, Yudelman M (2000). Governing the GM crop revolution: policy choices for developing countries.Intl.Food Policy Res. Inst. http://www.ifpri.org/sites/default/files/pubs/2020/dp/2020dp33.pdf.Do wnloaded April 2012.

Renn O (2008). Risk governance: coping with uncertainty in a complex world. Earthscan/James \& James:1-443.
Secretariat of the Convention on Biological Diversity (2000). Cartagena Protocol on Biosafety to the Convention on Biological Diversity: text and annexes,Montreal. http://www.cbd.int/doc/legal/cartagenaprotocol-en.pdf. Downloaded May 2012.

South Africa (1972).Foodstuffs, Cosmetics and Disinfectants Act of 1972, updated by Act No 39, 2007, Government Gazette 32012, 20 March 2009. http://www.daff.gov.za. Downloaded April 2012.

South Africa (1997).Genetically Modified Organisms (Act No. 15, 1997), Government Gazette 18029: 323, May 1997; as amended (Act No 23, 2007), Government Gazette 29803: 502, April 2007; and Regulations (2010), Government Gazette 32966: 120, 26 February 2010. http://www.daff.gov.za. Downloaded April 2012.

South Africa (2000a). Promotion of Access to information (Act no. 2 , 2000), Government Gazette 20852/416, 3 February 2000.http://www.justice.gov.za. Downloaded April 2012.

South Africa (2000b). Promotion of Administrative Justice (Act No.3, 2000). Government Gazette 20853/416, 3 February 2000. http://www.justice.gov.za. Downloaded April 2012.

South Africa (2001).A national Biotechnology strategy for South Africa, Department of Science and Technology.http://www.pub.ac.za/pdfs/biotechstrategy_2002.pdf. Downloaded April 2012.

South Africa (2003).Natural Scientific Professions Act (Act No. 27, 2003). Government Gazette 25774/461, 28 November 2003; and, recommended consultation fees, Board Notice 43, 2011. Government Gazette 34072, 2011.http://www.sacnasp.org.za. Downloaded April 2012.

South Africa (2004).National Environmental Management Biodiversity Act (Act No. 10, 2004), ch5 pt3 s78, Government Gazette 26436: 467, 7 June 2004: 62-64. http://www.environment.gov.za. Downloaded April 2012.

South Africa (2008).Consumer Protection Act (Act No. 68 of 2008), Government Gazette 32186/526, 29 April 2009; and Regulations (R 293, 1 April 2011). Government Gazette 34180/550 of 1 April 2011. http://www:thedit.gov.za. Downloaded April 2012.

Stirling EA, Dreyer M, Renn O, Vos E, Wendler F (2009). The need for change, in Food safety governance: integrating science, precaution and public involvement, Springer-Verlag, Berlin.

Wentholt MTA, Rowe G, König A, Marvin HJP, Frewer LJ (2009). The views of key stakeholders on an evolving food risk governance framework: results from a Delphi study. Food Policy 34:539-548. 